\title{
THE MAKING OF THE MGIMO LINGUISTICS JOURNAL: FROM PHILOLOGY TO POLYGLOT STUDIES
}

\author{
Tatiana Ivushkina \\ Moscow State Institute of International Relations (University) \\ 76, Prospekt Vernadskogo, Moscow, 119454, Russia
}

$\mathrm{I}$ would like to welcome everybody who joined our event today and thank you all for your contribution to our journal.

The conference materials on polyglottery and efficient methods of teaching/learning foreign languages presented at different international conferences speeded up the changes made to our journal not only in terms of its format but its content as well. They helped us find a new niche in research and open new vistas for the development of the journal. This new field - polyglottery - resonates with the aims and goals of our institution, Moscow State Institute of International Relations, which is multinational, multilingual and highly diverse, a real symbol of polyglottery. It trains specialists in the field of international relations, journalism and sociology, economics and business, law and many other disciplines, for international organizations and diplomatic missions. More than 50 foreign languages are taught here, as nowhere else. Languages are a strong side of the educational program and its priority. Our university is seen as the institution where students have a very high level of language skills, and the language professors are more than anywhere else focused on the methodology of teaching/learning languages and, undoubtedly, interested in the phenomenon of polyglottery, which provides us with new methods used by polyglots to enhance the learning and teaching process. Our journal, as we believe, can become a suitable platform for discussions, exchange of ideas and research. It can also become your journal!

The changes made to the journal can also be seen as the result of Russia's signing the Bologna declaration in 2003 and moving to two-tier education in 2007, thus integrating into European educational space in line with the Bologna Process, which means unification of standards, new standards of publications, and visibility and availability of the published materials.

Speaking about Linguistics \& Polyglot Studies, a new title we have resorted to is to designate a new life and new opportunities for the journal. The making of Linguistics \& Polyglot Studies has been long: twenty-two years. If we look back on its history, it began in 1999, when it was founded as a collection of articles by professors and graduate students and included research papers under four main thematic headings: linguistics and cross-cultural communication, translation studies, cultural studies and cultural linguistics, and innovative methods of teaching foreign languages. The format was different and the quality of articles was lower as compared with that of the current issues (they did not include abstracts or the English version of metadata). At that time the journal was known as Philology or Philologicheskie Nauki. 
In 2015, a rebranding was carried out: MGIMO, the name of the university, was added to the title, so it came to be published as Philology at MGIMO. Up to the present, it has been a journal of the Higher Attestation Commission of the Russian Ministry of Science and Higher Education (VAK), which means a quality journal with quality articles enabling the candidates publishing their research papers to apply for academic degrees. So, Linguistics \& Polyglot Studies is the successor of Philology at MGIMO and its traditions. This new title, however, coexists with its predecessor, Philology at MGIMO (in Russian), which is a marker of MGIMO and the journal which has got its recognition and reputation not only in Russia. We intend to continue the journal's traditions and, at the same time, considerably increase its visibility around the world publishing innovative research papers. This new stage opens with this special issue and the introduction of a new theme into the focus of the journal, the theme of polyglottery.

As for the main sections of the updated journal, they are as follows: linguistics and cross-cultural communication, sociolinguistics, cognitive linguistics, translation studies, pragmatics, discourse analysis, literature and culture studies. We are open for innovative multidisciplinary research papers, and review articles. I should emphasize the fact that we accept articles in 10 languages: Russian, English, German, French, Italian, Spanish, Chinese, Japanese, Arabic and Hindi. And this is another strong side and advantage of Linguistics \& Polyglot Studies over other journals.

I would like to reiterate: with the publication of this special issue we have created a scholarly platform for the like-minded people, professionals who can use it for their benefit. I would like you to take this platform as the platform where we can ask and answer questions, suggest topics for discussions and new special issues of the journal, where we could invite our graduate students for presentations, discussions and other events. This platform can be anything we want it to be. You are welcome with your ideas and initiatives!

Tatiana Ivushkina, Doctor of Philology, is Academic Editor of Linguistics \& Polyglot Studies and Chair of Department of English No.3, Moscow State Institute of International Relations (MGIMO). Research interests: sociolinguistics, the language and culture of the upper classes in Great Britain and the USA, stylistics, literature, cultural linguistics. E-mail: tatiana.ivushkina@gmail.com 